\title{
Caracterización anatómica foliar de cuatro especies de orquídeas epífitas de Cuericí, Costa Rica
}

\section{Foliar anatomical characterization of four species of epiphytic orchids from Cuericí, Costa Rica}

\author{
Maria Victoria Ortiz Crúz ${ }^{1}$, Ayerin Carrodeguas González², Andrés Zúñiga Orozco ${ }^{3}$ \\ 1. Reserva de la Biosfera Sierra del Rosario, ECOVIDA, CITMA, Artemisa, Cuba, \\ mvortiz2697@gmail.com \\ 2. Investigadora. Instituto de Investigaciones Hortícolas Liliana Dimitrova. Mayabeque. Cuba, \\ genetica2@lilliana.co.cu \\ 3. Docente e Investigador. Carrera Ingeniería Agronómica. Universidad Estatal a Distancia (UNED). \\ San José, Costa Rica, azunigao@ uned.ac.cr
}

\section{RESUMEN}

Introducción: Los bosques montanos nubosos de Costa Rica son unos de los ecosistemas de mayor diversidad y abundancia de orquídeas, debido a la presencia continua o estacional de una cobertura de nubes sobre la vegetación. Los rasgos anatómicos son importantes caracteres para la identificación y clasificación dentro de Orchidaceae y ayudan a entender las tendencias en la evolución. Objetivo: Caracterizar la anatomía foliar de cuatro especies de orquídeas epífitas en el bosque nuboso de Cuericí, Costa Rica para ampliar el conocimiento sobre los caracteres foliares asociados con el hábito epífito. Además, se analizó su relación con los factores abióticos del medio donde habitan para dilucidar posibles adaptaciones de estas especies. Métodos: Alguno de los caracteres evaluados fueron grosor de la cutícula, tipo de hoja según la distribución de los estomas, tipo de mesófilo y presencia de los haces de fibras de esclerénquima. Resultados y discusión: Todas las especies presentan caracteres anatómicos foliares relacionados con los bosques montanos nubosos, solo en Camaridium wrightii se observaron algunos rasgos xerofíticos. Conclusiones: el grosor de la cutícula y posición de estomas entre especies varió posiblemente en función de las condiciones ambientales. Las células epidérmicas de mayor tamaño observadas en la superficie adaxial de la hoja en Stelis sp. y Masdevallia walteri puede estar relacionado a la no presencia de pseudobulbos. Se observaron haces de fibras de esclerénquima en el mesófilo de Camaridium wrightii, lo que le confiere resistencia mecánica a las hojas.

Palabras claves: Lepanthes wedlandii, Masdevellia walteri, Camaridium wrightii, Stelis sp., Orchidaceae,

taxonomía

\section{ABSTRACT}

Introduction: The montane cloud forests of Costa Rica are one of the ecosystems with the greatest diversity and abundance of orchids, due to the continuous or seasonal presence of cloud cover over the vegetation. Anatomical features are important characters for identification and classification within Orchidaceae and help to understand trends in evolution. Objective: To characterize the foliar anatomy of four species of epiphytic orchids in the Cuericí cloud forest, Costa Rica to expand the knowledge about the foliar characters associated with the epiphytic habit. In addition, their relationship with the abiotic factors of the environment where they live was analyzed to elucidate possible adaptations of these species. Methods: Some of the evaluated characters were cuticle thickness, leaf type according to the stomata distribution, mesophyll type and presence of sclerenchyma fiber bundles. Results and discussion: All species have foliar anatomical characters related to montane cloud forests, only in Camaridium wrightii some xerophytic features were observed. Conclusions: the thickness of the cuticle and the position of stomata between species possibly varied as a function of environmental conditions. The largest epidermal cells observed on the adaxial surface of the leaf in Stelis sp. and Masdevallia walteri may be related to the absence of pseudobulbs. Sclerenchyma fiber bundles were observed in the mesophyll of Camaridium wrightii, which gives the leaves mechanical resistance. Key words: Lepanthes wedlandii, Masdevellia walteri, Camaridium wrightii, Stelis sp., Orchidaceae, taxonomy 
Introducción si se tiene en cuenta que las primeras monocotiledóneas aparecieron en la Tierra hace 100 millones de años (m.a) y los fósiles más antiguos de orquídeas encontrados corresponden a principios del Mioceno (20 a 30 m.a.) (Serra et al. 2001). Aproximadamente 28.000 especies integran esta familia (Emeterio-Lara et al., 2016; Djordjević \& Tsiftsis, 2019; Smidt et al., 2020; Li et al., 2021) lo que la posiciona como la segunda más diversa de plantas con flores a nivel mundial, después de Asteraceae Bercht. \& J.Presl (Cascante-Marín \& Trejos 2019; Li et al., 2021). Su gran diversidad se debe a la plasticidad de estas plantas a diferentes ambientes, lo cual ha sido facilitado por una serie de adaptaciones desarrolladas a lo largo de la evolución (e.g., pseudobulbos que almacenan agua y nutrientes, raíces cubiertas por velamen, hojas suculentas) (Díaz-Álvarez et al., 2019). Sin embargo, en las últimas décadas debido a su alto valor ornamental y medicinal ha aumentado la sobreexplotación en la naturaleza de muchas de sus especies, lo cual ha traído consigo la disminución del tamaño de sus poblaciones o que algunas estén próximas a la extinción local (Vega et al., 2015; Li et al., 2021). A esto se suma la vulnerabilidad de las orquídeas a cambios ambientales debido a la dependencia que tienen con agentes del biótico específico (hongo micorrícico y polinizadores) durante su ciclo de vida (Izuddin et al., 2019).

En Costa Rica la familia se encuentra bien representada taxonómicamente, albergando una porción significativa de la orquideoflora mundial y de Mesoamérica (Crain \& Fernández, 2020). Con casi 1600 especies de orquídeas reportadas, Costa Rica posee una de mayores riquezas de orquídeas en América tropical, superada solo en la región por Brasil, Colombia, Ecuador y Perú. Sin embargo, dada su pequeña extensión territorial $\left(51100 \mathrm{~km}^{2}\right)$ probablemente tenga la proporción de especie-área de orquídea más alta en el mundo (Karremans \& Bogarín, 2013). La orquideoflora de Costa Rica ha sido ampliamente estudiada, documentándose la diversidad, biología y distribución de sus especies (Crain \& Frennadez, 2020), por algunas de las figuras más renombrados de los siglos XIX y XX (Karremans \& Bogarín, 2013).

En el territorio costarricense el mayor número de especies se encuentra fundamentalmente en la cordillera de Tilaran, la Cordillera Central, la cordillera de Guanacaste y en las partes norteñas de la Cordillera de Talamanca (Crain \& Fernández, 2020). La mayoría de estas, al igual que en otras regiones del Neotrópico, se distinguen por su hábito epífito y alcanzan su mayor diversidad en los bosques montanos nubosos (Cascante-Marín \& Trejos, 2019). Estos bosques se caracterizan por un rocío persistente o nubes a nivel de la vegetación, lo que resulta en una reducción de la luz solar directa, que favorece la presencia de epífitas (Vega \& Rodríguez, 2018). En la actualidad lamentablemente los bosques nubosos son susceptibles a la fragmentación y a los efectos del cambio climático (Cascante-Marín \& Trejos, 2019), y en 
ellos las poblaciones de orquídeas epífitas se encuentran restringidas y con un pequeño número de individuos (Pérez-Escobar et al., 2017).

Los rasgos anatómicos son importantes caracteres para la identificación y clasificación dentro de Orchidaceae, siendo estudiados en varios géneros (e.g., Acostaea, Barbosella, Brachinionidium, Caladenia, Cryptophoranthus, Dracula, Dresslerella, Dryadella, Lepanthes, Masdevallia, Rhizobium, Ophrys, Orchis, Vanda entre otros). Además, dichos caracteres han mostrado tener una relación con las adaptaciones ecológicas de las orquídeas (Rindyastuti et al., 2018). Por ejemplo, las orquídeas que crecen en áreas muy iluminadas poseen una cutícula gruesa como adaptación a la intensa radiación solar que funciona como una barrera para reducir la transpiración (Moreira et al., 2013). También, estos caracteres contribuyen a evidenciar las tendencias en la evolución de las plantas, permiten establecer diferencias diagnósticas con el fin de profundizar en el conocimiento de estas especies y obtener una herramienta para definir su identidad taxonómica (Novoa \& Arambarri, 2016). Actualmente, la mayoría de estudios sobre orquídeas en Costa Rica incluyen métodos moleculares (Thangavelu \& Muthu, 2017). Basado en lo anterior, el objetivo del presente estudio es caracterizar la anatomía foliar de cuatro especies de orquídeas epífitas en el bosque nuboso de Cuericí, Costa Rica, para ampliar el conocimiento sobre los caracteres foliares asociados con el hábito epífito. Además, se analizó su relación con los factores abióticos del medio donde habitan para dilucidar posibles adaptaciones de estas especies.

\section{Materiales y métodos}

\section{1. Área de muestreo}

La recolecta del material para el estudio anatómico foliar se realizó en el bosque montano nuboso que rodea a la estación biológica Cuericí $\left(9.555000^{\circ}\right.$ latitud norte, $-83.667778^{\circ}$ longitud oeste, 2865 msnm), ubicada en la comunidad de Alto Jaular, distrito Rivas, en el cantón de Pérez Zeledón, Costa Rica (Figs. 1 A-B). El área se caracteriza por presentar una humedad relativa promedio anual de 80 a 90\%, una temperatura media anual de $8^{\circ} \mathrm{C}$ y una tasa anual de precipitaciones de $6500 \mathrm{~mm}$ (Vega \& Rodríguez, 2018).



Figura 1. Ubicación de la estación biológica Cuericí (A) y vistas del bosque nuboso que la rodea (B). Fotos: A: Google Earth. B: Fuente propia. 


\section{Especies}

Se seleccionaron cuatro especies de orquídeas epífitas que crecen en el bosque nuboso del área de conservación de Cuericí, ellas fueron: Lepanthes wedlandii Rchb. f. (Figs. 2 A), Masdevellia walteri Luer. (Figs. 2 B) y Stelis sp. y Camaridium wrightii Schltr. El criterio de selección fue la presencia de flores, estado reproductivo que facilitó la identificación de estas especies. Las tres primeras especies se encontraron creciendo a plena sombra, mientras que la última fue recolectada en un lugar más expuesto a los rayos solares. Todos los individuos fueron plantas adultas, en estado de floración y que no presentaban evidencias de ataques de patógenos y herbívoros.

Lepanthes wendlandii: Tallo 5-19 cm, vaina lepanthoidea diminutamente ciliadas. Pseudobulbos ausentes. Hoja erecta, lámina dispuesta horizontalmente, eliptica, ligeramente acuminada, levemente carnosa. Masdevellia walteri: Tallos de 2-3.5 cm. Pseudobulbos ausentes. Lámina elíptica, carnosas, dispuesta verticalmente.

Stelis sp.: Cespitosa; tallos erectos, con una hoja terminal. Pseudobulbos ausentes. Lámina conduplicada, obovada, carnosas, dispuesta verticalmente.

Camaridium wrightii: Tallos ramificados, pseudobulbos con 1-4 hojas terminales. Lámina dística, conduplicada, peciolada, levemente carnosa, dispuestas casi verticalmente.

\section{Procesamiento de las muestras}

El estudio anatómico de las especies se realizó a partir de 12 individuos, tres por especie; de cada individuo se recolectó dos hojas maduras, para un total de 24 hojas. A cada hoja se le realizó cortes transversales a mano alzada a nivel de su porción media. Una vez realizados los cortes, estos fueron blanqueados en una solución de hipoclorito de sodio (5\%) hasta que no se observó ningún rastro de clorofila en ellos. Posteriormente fueron realizados tres lavados con agua para limpiar los tejidos y eliminar cualquier rastro de la solución blanqueadora. Seguidamente, los cortes fueron teñidos con safranina y lavados nuevamente en agua suficiente para que no quedaran excesivamente teñido. Por último, después de la tinción de las secciones transversales, se procedió a su montaje en preparaciones semipermanentes.


Figura 2. Flor de dos de las especies estudiadas. A: Lepanthes wedlandii; y B: Masdevellia walteri. Fotos: Jorge de la Cruz. 


\section{Caracteres evaluados}

Los caracteres anatómicos foliares fueron observados en un microscopio óptico marca Olympus a un aumento de 10× y 40×; antes y después de su tinción. Además, de ser registrados a través de microfotografías. Los caracteres anatómicos analizados fueron:

\section{- $\quad$ Epidermis}

Forma de las células epidérmicas según Dilcher (1974) / Tamaño de las células epidérmicas (adaxiales respecto a las abaxiales) / Número de capas de células epidérmicas

\section{- Tricomas}

Presencia y ubicación de tricomas

\section{- Cutícula}

Grosor de la cutícula: se comparó el grosor de la cutícula con la altura de su correspondiente célula epidérmica. Si el grosor de la cutícula es menor que la mitad de la altura de su correspondiente célula epidérmica, se clasificó como una cutícula fina, si el grosor era igual o mayor que la mitad, se clasificó como cutícula gruesa.

\section{- Estomas}

Tipo de hoja según la distribución de los estomas según Reyes-López et al. (2015) / Posición de los estomas respecto a la epidermis (mismo nivel o hundidos).

\section{- Mesófilo}

Tipo de mesófilo según Valla (2004) / Número de capas del mesófilo / Tipo de parénquima que conforma el mesófilo / Forma de las células del parénquima / Presencia de engrosamientos espiralados en la pared primaria de las células del parénquima.

\section{- Haces vasculares}

Número de series

\section{- Caracteres específicos}

Presencia de tricomas / Presencia de haces de fibras de esclerénquima (subepidérmicos, en el mesófilo y en los haces vasculares). 


\section{Resultados}

Descripción anatómica foliar de las especies estudiadas:

Lepanthes wedlandii: Hojas hipoestomáticas. Cutícula adaxial y abaxial fina. Epidermis uniseriada, con células epidérmicas rectangulares, las adaxiales y abaxiales de igual tamaño. Tricomas ausentes. Estomas al mismo nivel de las células epidérmicas. Mesófilo heterogéneo, 8-11 células de grosor; parénquima incoloro adaxial al clorofílico, de 3 células de grosor, compuesto por poliédricas sin engrosamientos espiralados en su pared primaria; parénquima clorofílico de 8 células de grosor, compuesto por células redondeadas. Haces vasculares de varios tamaños, distribuidos en una serie en el parénquima clorofílico; esclerénquima ocurre en forma de vainas vasculares conspicuas y completas.

Masdevallia walteri: Hojas anfiestomáticas. Cutícula adaxial y abaxial fina. Epidermis uniseriada, con células epidérmicas rectangulares, las adaxiales de mayor tamaño. Tricomas ausentes. Estomas hundidos. Mesófilo heterogéneo, 10-13 células de grosor; parénquima incoloro de 4 células de grosor, compuesto por células poliédricas con engrosamientos espiralados en su pared primaria; parénquima clorofílico de 9 células de grosor, compuesto por células redondeadas. Haces vasculares de varios tamaños, distribuidos en una serie en el parénquima clorofílico; esclerénquima ocurre en forma de vainas vasculares conspicuas y completas.

Stelis sp.: Hojas anfiestomáticas. Cutícula adaxial y abaxial fina. Epidermis uniseriada, con células epidérmicas rectangulares, las adaxiales de mayor tamaño. Tricomas glandulares en depresiones epidérmicas presentes en ambas superficies foliares. Estomas al mismo nivel que las demás células epidérmicas. Mesófilo heterogéneo, 11-16 células de grosor; formado por un parénquima incoloro adaxial de 4 células de grosor, abaxial uniseriado; parénquima en empalizada de 2 células de grosor, compuesto por células columnares; parénquima clorofílico de 10 células de grosor, compuesto por células oblongas. Haces vasculares de varios tamaños, distribuidos en una serie en el parénquima clorofílico; esclerénquima ocurre en forma de vainas vasculares conspicuas y completas.

Camaridium wrightii: Hojas hipoestomáticas. Cutícula adaxial y abaxial gruesa. Epidermis uniseriada, con células epidérmicas rectangulares, las adaxiales y las abaxiales de igual tamaño. Tricomas glandulares en depresiones epidérmicas presentes en ambas superficies foliares. Estomas al mismo nivel que las demás células epidérmicas, con rebordes cuticulares externos. Mesófilo heterogéneo, 6-9 células de grosor; parénquima incoloro adaxial al clorofílico, de 3 células de grosor, compuesto por células poliédricas con engrosamientos espiralados en su pared primaria; parénquima clorofílico de 6 células de grosor, compuesto por células redondeadas. Haces de fibras de esclerénquima en dos series, la primera en la superficie abaxial, una capa después de las células epidérmicas y la otra de haces más grandes distribuidos entre el parénquima incoloro. Haces vasculares de varios tamaños, distribuidos en una serie en el parénquima clorofílico; esclerénquima ocurre en forma de vainas vasculares conspicuas y completas. 
En sección transversal se observó en Lepanthes wedlandii (Fig. 3A), Stelis sp. y Masdevallia walteri una cutícula fina que recubre el estrato de células epidérmicas, excepto en Camaridium wrightii donde es gruesa (Fig. 3B). Todas las especies presentaron una epidermis monoseriada y en el caso de Masdavallia walteri y Stelis sp. las células de la región adaxial presentaron un mayor tamaño que las restantes. Además, en Stelis sp. (Fig. 4) y Camaridium wrightii presentaron en ambas superficies foliares tricomas glandulares en depresiones epidérmicas.

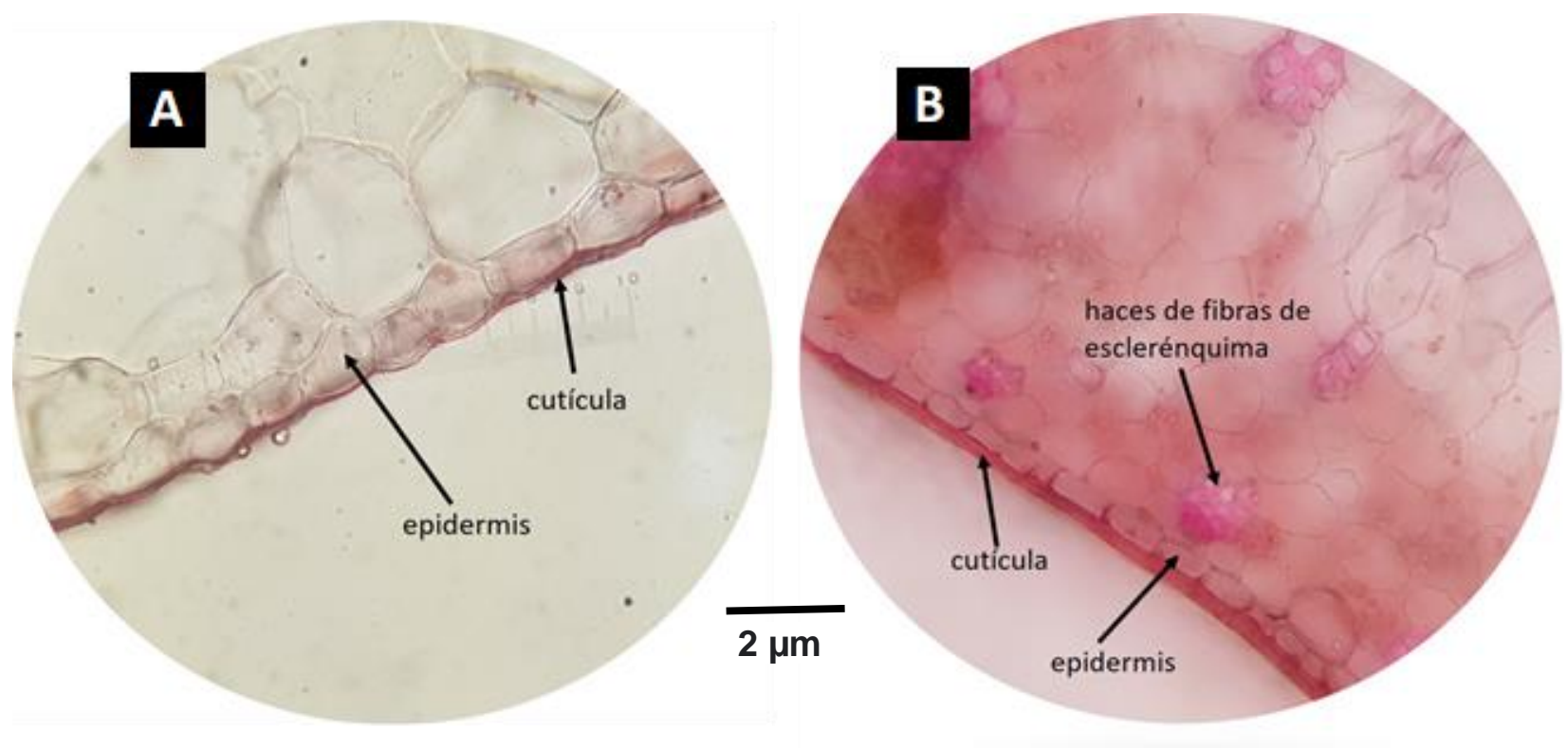

Figura 3. Sección transversal de una porción de la epidermis de la hoja de A. Lepanthes wedlandii (10x).

B. Camaridium wrightii $(10 \times)$. Fotos: Fuente propia

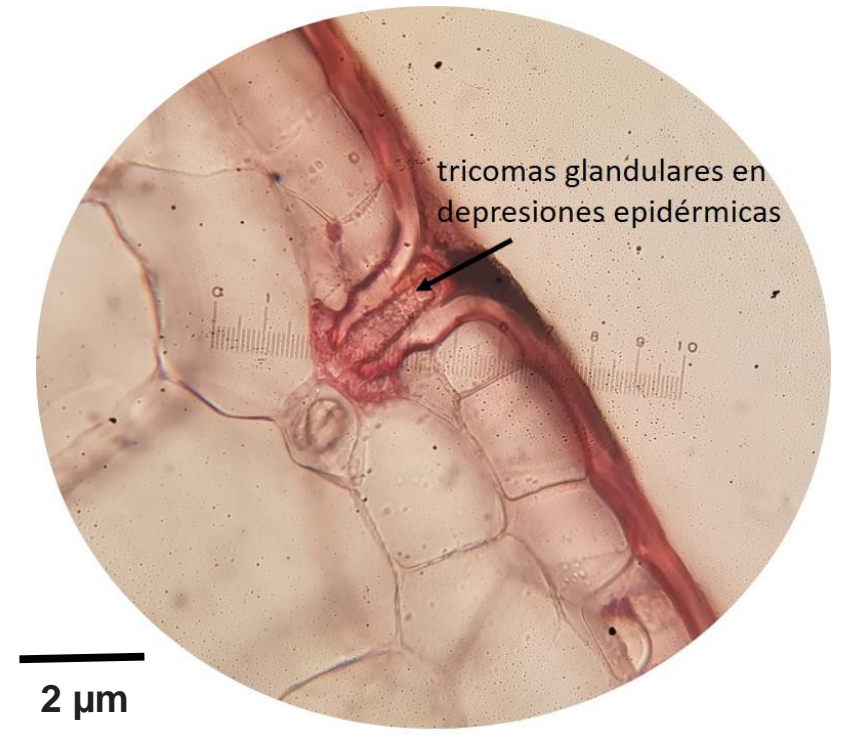

Figura 4. Sección transversal de la lámina foliar de Stelis sp. (10×). Fotos: Fuente propia

De acuerdo con la distribución de los estomas en su superficie, las hojas de Stelis sp. y 
Masdevallia walteri son anfiestomáticas, mientras que las de Lepanthes wedlandii y Camaridium wrightii son hipoestomáticas. Las estomas se observaron al mismo nivel de las células epidérmicas en Lepanthes wedlandii, Stelis sp. (Fig. 5A), y Camaridium wrightii (Fig. 5B); en esta última presentan rebordes cuticulares externos que dan lugar a una cámara supraestomática. Mientras que en Masdevallia walteri los estomas están ligeramente hundidos.

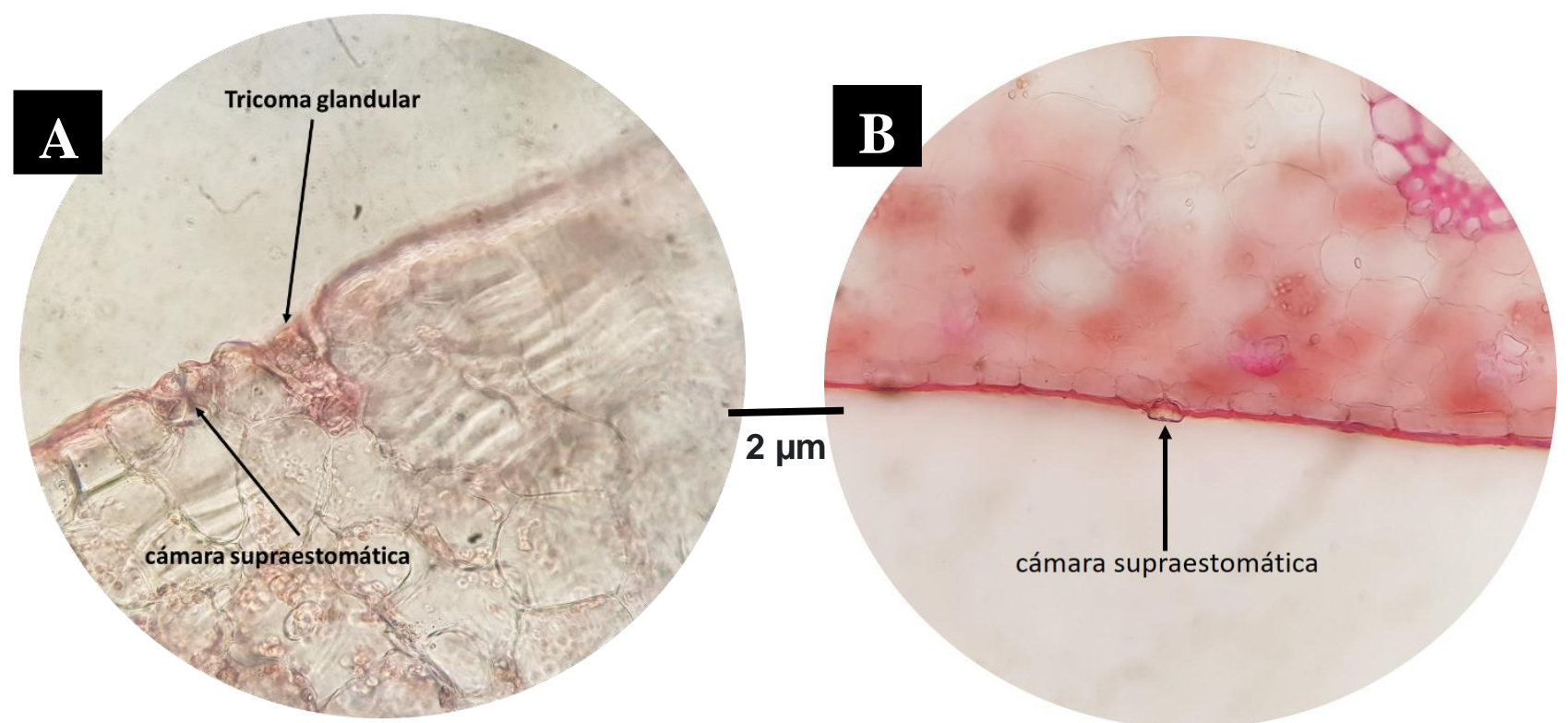

Figura 5. Estomas en (A) Stelis sp. (10x) y (B) Camaridium wrightii (10x). Fotos: Fuente propia

El mesófilo en las cuatro especies estudiadas presentó una estructura heterogénea. En Stelis sp. se observó en la región adaxial un parénquima en empalizada de células de forma columnar que poseen engrosamientos espiralados (Fig. 6) y en la región abaxial un parénquima clorofílico de células redondeadas y de tamaño variable. Además, en todas las especies se observó en la región adaxial un parénquima incoloro de células poliédricas que poseen también engrosamientos espiralados en su pared, excepto en Lepanthes wedlandii donde no se presentan estos engrosamientos. El parénquima incoloro se continua de un parénquima clorofílico cuyas células son redondeadas y de tamaño variable, excepto en Stelis sp. donde se continua con un parénquima de células columnares (parénquima en empalizada). 


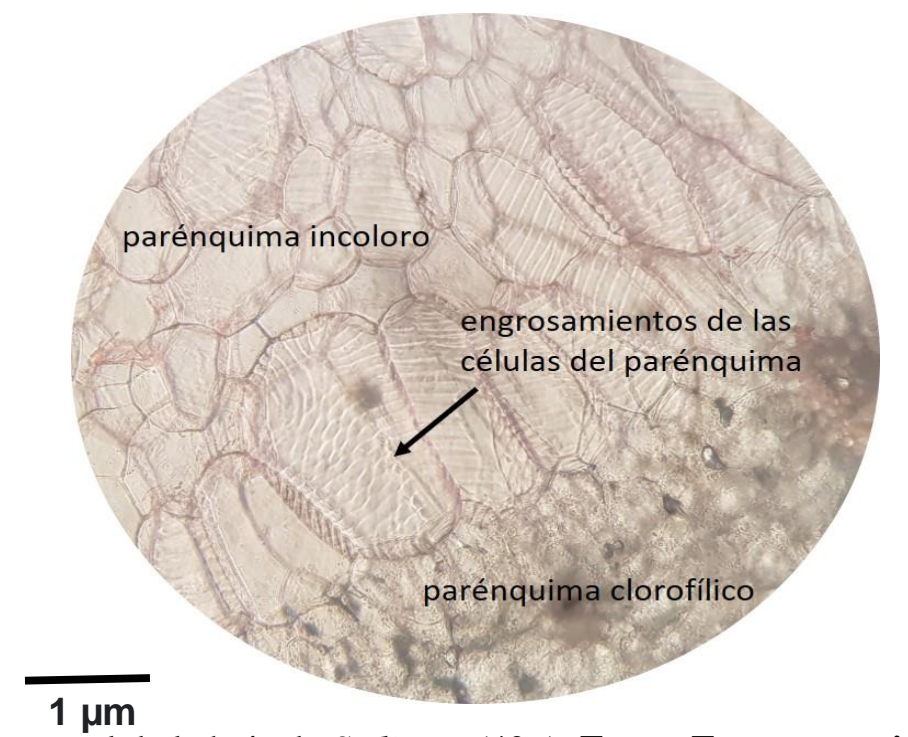

Figura 6. Sección transversal de la hoja de Stelis sp. (40×). Fotos: Fuente propia

Solo en Camaridium wrightii se observaron haces de fibras de esclerénquima en el mesófilo (Fig. 3B), los cuales se sitúan en dos series en el mesófilo, una de ellas de haces pequeños una capa por debajo de la epidermis en la superficie abaxial y la otra de haces más grandes distribuidos entre el parénquima incoloro. Además, en todas las especies se observó haces vasculares de varios tamaños, distribuidos en una serie en el mesófilo clorofílico, donde el esclerénquima ocurre en forma de vainas vasculares conspicuas y completas; separando el xilema del floema (Fig. 7).

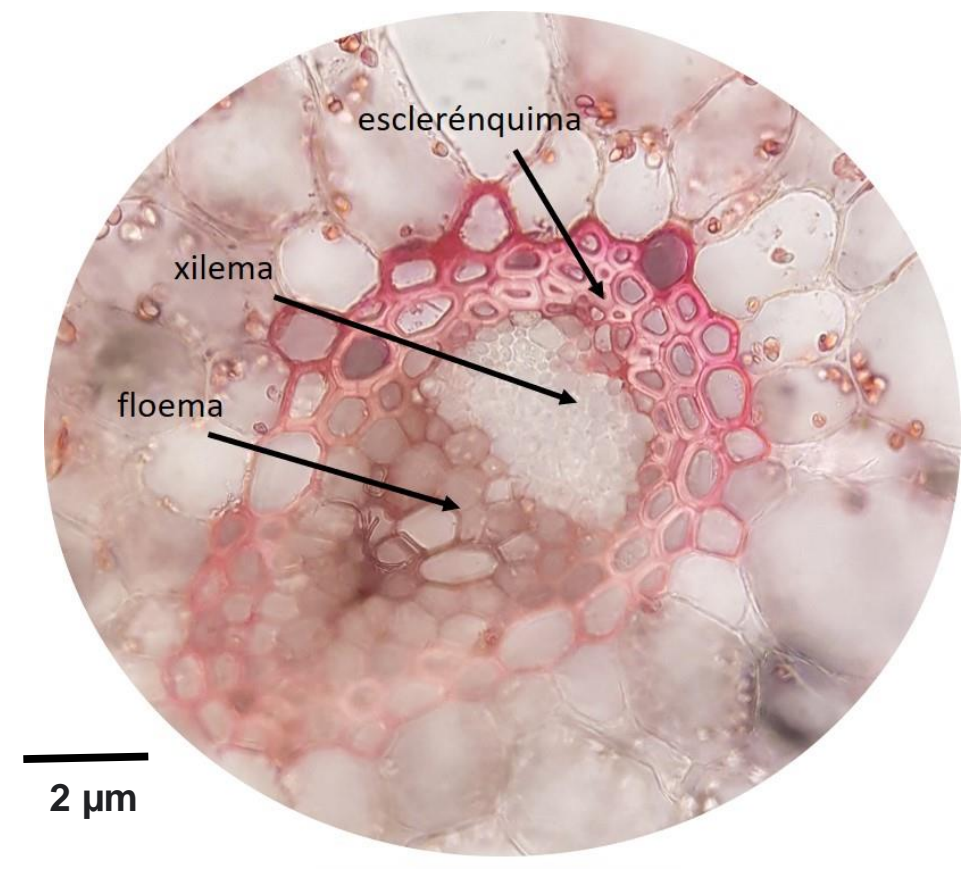

Figura 7. Haz vascular principal de Masdevallia walteri (10×), se observa esclerénquima, xilema y floema. Fotos: Fuente propia 


\section{Discusión}

La cutícula es la capa más externa de las hojas de la orquídea y juega un papel importante en la interacción de plantas con el ambiente, ya que contribuye a reducir la captación de radiación solar, la temperatura y la transpiración (Domínguez et al., 2011). Las especies estudiadas crecen en el bosque montano nuboso, donde la nubosidad modifica las condiciones atmosféricas y reduce la radiación solar y el déficit de vapor de agua (Cascante-Marín \& Trejos, 2019). En estas condiciones ambientales la tasa de evapotranspiración se reduce (Vega \& Rodríguez, 2018), por ello las especies epífitas que habitan en este medio no necesitan una cutícula gruesa para evitar la desecación, lo cual se pone de manifiesto en Lepanthes wedlandii, Stelis sp. y Masdevallia walteri. La presencia de una cutícula gruesa en Camaridium wrightii podría deberse a la tendencia de que especies más expuestas a los rayos solares presentan hojas y cutículas más gruesas, lo cual fue corroborado por Arévalo et al. (2011) para algunas especies de orquídeas epífitas (e.g., Rodriguezia lehmannii Rchb.f., Hirtzia escobarii Dodson, Elleanthus purpureus (Rchb.f) Rchb.f, Pleurothallis cordifoila Rchb.f. \& H. Wagener y Stelis sp.).

Stelis sp. y Masdevallia walteri presentan hojas anfiestomáticas, es decir con estomas en ambas superficies foliares. Por el contrario, Lepanthes wedlandii y Camaridium wrightii tienen hojas hipoestomáticas, es decir con estomas solo en la superficie abaxial. Ello podría estar relacionado con que estas especies poseen hojas finas, poco carnosas, con poca capacidad de almacenar agua, por lo que la ausencia de estomas en la superficie adaxial es una manera de reducir la pérdida de agua por transpiración. Además, la presencia de estomas rodeados por rebordes cuticulares externos que dan lugar a una cámara supraestomática en Camaridium wrightii, podría permitir la existencia de un compartimiento de aire húmedo que protege a los estomas, lo cual es también una adaptación para reducir la transpiración (RiverónGiró et al., 2017; Ortiz-Crúz \& Morales, 2018).

En cuanto a las células epidérmicas se presentó mayor tamaño en la superficie adaxial de la hoja en Stelis sp. y Masdevallia walteri, lo que podría estar relacionado con la ausencia de pseudobulbos en estas especies y esto podría inducir a presentarse adaptaciones en sus hojas para compensar la ausencia de esta estructura (Oliveira \& Sajo, 1999). Según Scatena \& Nunes (1996), Oliveira \& Sajo (1999), Arévalo et al. (2011) y Rindyastuti et al. (2018), esta característica relacionada con la función de reserva de agua.

Los tricomas glandulares en depresiones epidérmicas en Stelis sp. también fue reportado por Arévalo et al. (2011) para el género. Según este autor, dicha estructura en la subtribu Pleurothallidinae no está involucrada en procesos de toma de agua, sino que su función podría consistir en la secreción de mucílago, que actuaría en reducir la transpiración y así se induce un efecto de compensación por la ausencia de pseudobulbos en esta especie.

La presencia en Stelis sp., Masdevallia walteri, Lepanthes wedlandii y Camaridium wrightii de un mesófilo con un parénquima incoloro, adaxial al parénquima clorofílico, podría ser una adaptación 
en estas especies a aumentar la tasa fotosintética, ya que este podría potenciar la captación de luz solar, recurso que es limitante en el bosque montano nuboso (Valladares \& Sánchez-Gómez, 2004).

Solo en Camaridium wrightii se observó la presencia de haces de fibras de esclerénquima en el mesófilo, estos les confieren a las hojas de las especies que los poseen resistencia mecánica en caso de deshidratación (Oliveira \& Sajo, 1999). La ausencia de estas estructuras en las restantes especies podría deberse a que, al vivir en lugares menos expuestos a la radiación solar que Camaridium wrightii, se ven menos afectadas por la deshidratación. La presencia o no de haces de fibras de esclerénquima en el mesófilo es un carácter diagnostico en la determinación y diferenciación de especies (Rindyastuti et al., 2018).

\section{Conclusiones}

- Lepanthes wedlandii, Stelis sp. y Masdevallia walteri presentaron una cutícula fina debido a que la tasa de evapotranspiración se reduce al máximo por las condiciones ambientales, mientras que Camaridium wrightii presentó una cutícula gruesa.

- Stelis sp. y Masdevallia walteri presentaron hojas anfiestomáticas mientras que Lepanthes wedlandii y Camaridium wrightii hojas hipoestomáticas, factor directamente relacionado con la disponibilidad de agua.

- La presencia de células epidérmicas de mayor tamaño observadas en la superficie adaxial de la hoja en Stelis sp. y Masdevallia walteriy puede estar relacionado a la no presencia de pseudobulbos, por lo que las hojas deben asumir el almacenaje de agua.

- Se observó un parénquima incoloro, adaxial al parénquima clorofílico, lo cual podría ser una adaptación en estas especies para aumentar la tasa fotosintética.

- Se observaron haces de fibras de esclerénquima en el mesófilo en Camaridium wrightii, lo que les confiere resistencia mecánica a las hojas.

\section{Referencias}

Ackerman, J. D. (2014). Orchid flora of the Greater Antilles. (pp. 625). New York: New York Botanical Garden Press.

Arévalo, R., Figueroa, J. \& Madriñan, S. (2011). Anatomía foliar de ocho especies de orquídeas epífitas. Lankesteriana, 11 (1): 39-54.

Cascante-Marín, A. \& Hernández, C. T. (2019). Diversidad y vulnerabilidad de la flora orquideológica de un bosque montano nuboso del Valle Central de Costa Rica. Lankesteriana. 19(1): 31-55. 
http://dx.doi.org/10.15517/lank.v19i1.37031

Cetzal-Ix, W., Noguera-Savelli, E., Jáuregui, D., \& Carnevali, G. (2013). Anatomía foliar comparada y sistemática del clado Trichocentrum con énfasis en Cohniella (Asparagales: Orchidaceae). Revista de Biología Tropical, 61(4): 1841-1858.

Clade-age-dependent diversification under high species turnover shapes species richness disparities among tropical rainforest lineages of Bulbophyllum (Orchidaceae). BMC Evolutionary Biology, 19(93), 116. Doi: 10.1186/s12862-019-1416-1

Crain, B., \& Fernández, M. (2020). Biogeographical analyses to facilitate targeted conservation of orchid diversity hotspots in Costa Rica. Biodiversity research, 26, 853-866. doi: 10.1111/ddi.13062

Díaz-Álvarez, E., Felix, D., \& Barrera, E. (2019). Elemental and isotopic assessment for Colombian orchids from a montane cloud forest: a baseline for global environmental change. Acta Physiologiae Plantarum, 41:99. doi: 10.1007/s11738-019-2893-y

Djordjević, V., \& Tsiftsis, S. (2019). Patterns of orchid species richness and composition in relation to geological substrates. Wulfenia, 26, 1-21

Domínguez, E., Cuartero, J., \& Heredia, A. (2011). An overview on plant cuticle biomechanics. Plant Science, 181 (2), 77-84.

Emeterio-Lara, A., Palma-Linares, V., Vázquez-García, L. M, \& Mejía-Carranza, J. (2016). Usos y comercialización de las orquídeas silvestres en la región sur del Estado de México. Polibotanica, 42, 197-214

Freudenstein, J. \& Chase, M. (2015). Phylogenetic relationships in Epidendroideae (Orchidaceae), one of the great flowering plant radiations: progressive specialization and diversification. Annals of botany, 115 (4), 665-681.

Givnish, T. J., Spalink, D., Ames, M., Lyon, S. P., Hunter, S. J., Zuluaga, A., \& Endara, L. (2015). Orchid phylogenomics and multiple drivers of their extraordinary diversification. Proceedings of the Royal Society B: Biological Sciences, 282(1814), 20151553. https://doi.org/10.1098/rspb.2015.1553

Hammel, B. E., Grayum, M. H., Herrera, C., \& Zamora, N. (2004). Manual de Plantas de Costa Rica Volumen III Monocotiledóneas (Orchidaceae-Zingiberaceae). Monographs in systematic botany. (pp. 97).

Izuddin, M., Yam, T., \& Webb, E. (2019). Germination niches and seed persistence of tropical epiphytic orchids in an urban landscape. Journal of Plant Research, 132, 383-394. Doi: 10.1007/s10265019-01110-0.

Karremans, A. P., \& Bogarín, D. (2013). Costa Rica, Land of Endless Orchids. Orchids, 82(7), 408-411.

Li, H., Xiao, W., Tong, T., Li, Y., Zhang, M., Lin, X., ... Guo, X. (2021). The specific DNA barcodes based on chloroplast genes for species identification of Orchidaceae plants. Scientific Reports, 11(1), 1- 
15. Doi: $10.1038 / \mathrm{s} 41598-021-81087-\mathrm{w}$

Moreira, A., Filho, J., Isaias, R. (2013). Structural adaptations of two sympatric epiphytic orchids (Orchidaceae) to a cloudy forest environment in rocky outcrops of Southeast Brazil. Revista de Biologia Tropical 61, (3), 1053-1065.

Novoa, M. C. \& Arambarri, A. M. (2016). Importancia de La anatomía foliar en la caracterización de Commelinaceae Medicinales en la región Rioplatense (Argentina). Boletín de La Sociedad Argentina de Botánica, 51(3): 419-27. doi: 10.31055/1851.2372.v51.n3.15387.

Oliveira, V. D. C., \& Sajo, M. D. G. (1999). Anatomia foliar de espécies epífitas de Orchidaceae. Revista Brasileira de Botânica, 22(3): 365-374.

Ortiz-Crúz, M. V. \& Martínez, A. M. (2018). Caracterización anatómica foliar de cuatro especies cubanas del género Tolumnia (Orchidaceae). Revista del Jardín Botánico Nacional, 39: 91-96.

Pérez-Escobar, O. A., Chomicki, G., Condamine, F., Karremans, A., Bogarín, D., Matzke, N., Silvestro, D., \& Antonelli, A. (2017). Recent origin and rapid speciation of Neotropical orchids in the world's richest plant biodiversity hotspot. New Phytologist, 215: 891-905. doi: 10.1111/nph.14629

Pridgeon, A. M., Solano, R., \& Chase, M. W. (2001). Phylogenetic relationships in Pleurothallidinae (Orchidaceae): combined evidence from nuclear and plastid DNA sequences. American Journal of Botany, 88(12), 2286-2308.

Reyes-López, D., Quiroz-Valentín, J., Kelso-Bucio, H. A., Huerta-Lara, M., Avendaño-Arrazate, C. H., \& Lobato-Ortiz, R. (2015). Caracterización estomática de cinco especies del género Vanilla. Agronomía Mesoamericana, 26(2), 237-246.

Rindyastuti, R., Nurfadilah, S., Rahadiantoro, A., Hapsari, L.\& Abywijaya, K. (2018). Leaf anatomical characters of four epiphytic orchids of Sempu Island, East Java, Indonesia: The importance in identification and ecological adaptation. Biodiversitas, 19(5), 1906-1918. Doi: 10.13057/biodiv/d190543

Riverón-Giró, F., Damon, A., García-González, A., Solís-Montero, L., Aguilar-Romero, O., RamírezMarcial, N. \& Nieto, G. (2017). Anatomy of the invasive orchid Oeceoclades maculata: ecological implications. Botanical Journal of the Linnean Society, 184, 94-112.

Saunders, D. A., Hobbs, R. J., \& Margules, C. R. (1991). Biological consequences of ecosystem fragmentation: a review. Conservation biology, 5(1), 18-32.

Scatena, v.l. \& Nunes, A. (1996). Anatomia de Pleurothallis rupestris Lindl. (Orchidaceae) dos campos rupestres. Boletim de Botânica da Universidade de São Paulo, 15, 35-43.

Serra. L., Pérez, B., Fábregat, C., \& Juárez, J. (2001). Orquídeas Silvestres De La Comunidad Valenciana. (pp. 366). Valencia: Generalitat Valenciana.

Smidt, E. D. C, Paez, M. Z., Vieria, L. D. N., Viruel, J., V. A, Balsanelli, E., ...\& Chase, M. W. (2020). 
Characterization of sequence variability hotspots in Cranichideae plastomes (Orchidaceae, Orchidoideae). PloS one, 15(1), e0227991

Thangavelu, M. \& Muthu, S. (2017). Vegetative anatomical adaptations of Epidendrum radicans (Epidendroideae, Orchidaceae) to epiphytic conditions of growth. Modern Phytomorphology 11, 117-130, 2017. doi: 10.5281/zenodo.1078523

Valladares, F., Aranda, I., \& Sánchez-Gómez, D. (2004). La luz como factor ecológico y evolutivo para las plantas y su interacción con el agua. En: Valladares, F (Ed). Ecología del bosque mediterráneo en un mundo cambiante. (pp. 335-369). Madrid: Ministerio de Medio Ambiente.

Vega, B., \& Rodríguez, F. (2018). Dinámica de la estructura del paisaje en el ecosistema de páramo y su relación con factores climáticos e incendios: Cerro de la Muerte (Buena Vista) 1992 y 2012. (tesis inédita de licenciatura). Universidad Nacional, Heredia, Costa Rica.

Vega, H., Mó, E., Cetzal-Ix, W., \& Carpenter, J. (2015). Usos tradicionales y medicinales de la orquídea matasequía (Prosthechea michuacana) en Honduras. Desde el Herbario CICY, 7, 94-98. 